\title{
O ANJO E SUAS METAS-MORFOSES
}

José Eduardo Martins*

\begin{abstract}
RESUMO: Francisco Mignone frente aos principios de uma estetica nacionalista proposta por Mário de Andrade. A adesāo necessária como fator de sobrevivência intelectual e artística. A Parte do Anjo (1947) e os anlagonismos. Temática: plágio e facilidade, talento e técnica, gènio inato e gênio feito, música nacional e internacional. anjo e demônio, dúvida dinâmica e dúvida que desconfia, Villa-Lobos e Camargo Guarnieri. Permanente pluralismo no pensamento de Mignone. Nacionalismo terminal e atuais correntes da música brasileira.
\end{abstract}

UNITERMOS: F. Mignone: A Parte do Anjo; pensamento pluralista.

Lembrar um autor em efeméride é muitas vezes motivo de constrangimento. O centenário de nascimento de Francisco Mignone é caso tipico. À certeza de uma das mais precisas e criativas escritas composicionais do Brasil, em toda a sua história, depara-se o constrangimento do olvido, pois um quase total obscurantismo se abateu sobre a sua obra após a morte, ocorrida em 1986. Enquanto presente, Mignone permanecia vigilante quanto à preservação de sua obra; aberto aos convites, seja como regente ou pianista, seja como conferencista ou membro de júris específicos. Essa atitude fez desenhar em tomo de si a aura que se expandiu pelo vasto território pátrio, levando in adendo o repertório, sempre difundido em termos brasileiros no que conceme à produção de concerto, hélas, de maneira restrita.

Da tríade de compositores que aderiu ou visitou a estética nacionalista, constituida por Villa-Lobos (1887-1959), Francisco Mignone (1897-1986) e Camargo Guarnieri (1907-1993), o segundo teria sido o que maior comprometimento circunstancial teve com o movimento.

Villa-Lobos, quase que consensualmente, posicionou-se como o mais ventilado compositor brasileiro extrafronteiras. A sua obra ultrapassaria rotulaçōes e adjetivos, e nem mesmo as polemicas que se formaram em tomo de seu nome conseguiriam

* Pianista e professor do Depto. de Música da ECA/USP. 
impedir o prestígio a cada espaço consolidado. As inclinaçōes de Villa-Lobos se voltaram, em grande parte, frise-se, naturalmente ao nacional ${ }^{1}$.

Tendo vinte anos a menos, Camargo Guarnieri sempre sofreria os efeitos da sombra provocada pelo autor das Bachianas. Em sendo mais jovem e em plena formação, submeter-se à emergente ideologia nacionalista professada por seu mestre, Mário de Andrade, obedece a uma certa logicidade. A ascendência mario-andradina perduraria, aliás, durante toda a existência de Camargo Guarnieri e a de muitos de seus epigonos, de maneira incisiva, inexorável, fidelíssima, fatalista. Essa submissão devocional de Camargo Guarnieri nāo impediria contudo a construção de uma obra monumental, polimorfa quanto aos gêneros, na qual o esmero constante - apesar de evolução menos sensivel - a dignifica como uma das mais significativas produzidas no Brasil.

Francisco Mignone diferencia-se de seus dois coevos na medida em que a sua submissão tardia aos ideais expressos com veemência por Máno de Andrade se processaria de maneira enfática aos olhos da ruidosa mini-intelligentzia voltada à estética nacionalista, mas cujo engajamento pleno teria sempre a égide de uma forte tendência atávica internacional, em termos melódicos e estruturais, jamais negada pelo compositor.

É notório que, apesar de desconfianças, aos olhos de Mário de Andrade, Francisco Mignone se submetera após as veementes críticas daquele à ópera $O$ Inocente, rigorosamente europeizada. Mário nāo esconde essa euforia pela vitória conseguida, referindo-se àqueles que o ouviram: "Jamais encontrei entre eles quem demonstrasse, como Francisco Mignone, um conhecimento mais íntimo, mais profundo e mais vasto da música"'.

Francisco Mignone foi uma das mais brilhantes inteligências brasileiras, num sentido geral, e, dos três compositores citados, aquele que mais soube camuflar intençōes. A fim de nāo permanecer marginalizado frente a uma corrente estética que, desde a emergência, mais e mais fincava raizes, pulverizando um passado musical estruturado em ideais europeus, era-lhe importante aderir. A não-vinculação - a se lerem os textos contundentes de Mário de Andrade anatematizando compositores coetâneos filiados a outras atitudes frente à música - à estética nacionalista por um autor do poder criativo de Francisco Mignone, significava o desterro da divulgaçāo, o isolamento exemplar.

Quando, em 1947, sai publicada A parte do Anjo (autocritica de um cinqüentenário), contendo cinco textos do compositor, estava-se no epicentro temporal de duas explosivas discussões estético-musicais ${ }^{3}$. Poder-se-iam ser consi-

1. Villa-Lobos, na essència essencial, pareceria nāo ter dependido de nenhum eleito especial. Rigorosos coetáneos ou imediatos seguidores, fossem eles compositores, musicistas ou outros, conscienle ou inconscientemente giraram em tomo de si como satélites de dimensóes variadas.

2. ANDRADE, Mário de. Francisco Mignone. In: MIGNONE, Francisco. A parte do Anjo. São Paulo, E. S. Mangione, 1947. p. 63.

3. Uma primeira, o Manifesto Música Viva de 1946, onde se encontra incisiva critica ao nacionalismo musical e tendo como signatários H.J. Koellreutter, Guerra Peixe, Eunice Calunda. Cláudio Sanloro. 
derados bálsamos os escritos de Francisco Mignone em relação às duas manifestaçōes temporalmente próximas. Em A Parte do Anjo não há radicalismos mas interpretaçōes até radicais, que o humor transforma. Colocações pessoais, processos em direção ao fazer música, plágio e facilidade, visitas ao nacional d'après Mário de Andrade, influências internacionais, o social na música de maneira bem tênue, o talento e a técnica, anjo e demônio, gènio nato e gênio feito, categorias de dúvidas e hilariantes episódios concernentes à sua ópera, O Contratador dos Diamantes.

A longa trajetória do compositor, obreiro até as fronteiras da morte, testemunham a fina ironia já contida em $A$ Parte do Anjo, o confessar adesāo, o incorporar preceitos do discurso de Máno de Andrade, repetindo-os inclusive - os do Ensaio sobre Música Brasileira - sem quaisquer constrangimentos. Senhas foram deixadas durante a existência, nas quais evidências claras de um despistamento fariam crer não ter Mário de Andrade se apercebido na dimensão devida, em vários momentos, dessa eterna vocação cosmopolita de Mignone, a serviço de uma visāo nacional sim, circunstancial também, numa parcela considerável de sua obra. A submissāo a partir mais acentuadamente dos anos 30 viria, como exemplo, de chamamentos de Mário de Andrade, como: "Ele inda está excessivamente atraido pela chamada 'música universal', sem reparar que a verdadeira universalidade, sinão a mais aplaudida, pelo menos a mais fecunda e enobrecedora, é a dos artistas nacionais por excelência"t.

Quando da aparição de A Parte do Anjo, cujo título foi aproveitado de um dos cinco textos de Mignone que compōem a pequena obra, três outros escritos, de Luiz Heitor Corrêa de Azevedo, Mário de Andrade (1939) e Liddy Chiaffarelli (biografia), completam a publicaçăo. Dos três, frise-se o de Luiz Heitor, introdutório, bem mais longo do que os cirico de Mignone. Denominado "Si alza la tela" e datado de 7 de abril de 1947, prima pela redundância, sobremaneira se for considerado o fato dos textos do compositor serem prioritánios.

Em seu texto, Luiz Heitor exalta Mário de Andrade e é fácil a detectação de dado essencial, seja ele o de que apenas após a conversāo aos ideários nacionalistas, Francisco Mignone passaria a ser um compositor engajado socialmente $e^{5}$. Confessa mesmo que no final dos anos 20, Máno de Andrade estava "movendo guerra de morte a todo o oficialismo italianizante do ambiente musical paulistano"6. E, num rasgo de plena adesāo aos ideários, Luiz Heitor sobrepōe às criaçōes de Mignone e de Mário de Andrade a idéia da integraçāo nacional: "A correspondência entre ambos é de particular interesse, pela transcendência das questōes versadas, a liberdade com que são abordadas e a autoridade dos signatários, participantes,

Edino Krieger: e a Carta Aberta gos músicos e criticos do Brasil, de 1950. escrita por Camargo Guamieri em plena defesa da estética nacionalista frente às idejas musicais já sedimentadas, advindas da Europa.

4. ANDRADE, Mátio. Mísica. doce música. São Paulo. L. G. Miranda, 1933. p. 316.

5. Necessário se laz reiterar sempre a permanente repetiçāo do discurso de Mário de Andrade das décadas de 20 e 30 pelos autores e historiadores da música brasileira, de Renato Almeida até, é de se lamentar. bem presentemente. o que demonstro prolongamento de preceitos que perderam a elicácia pelo esgotamento.

G. Cf. MIGNONE, Francisco. Op. cit. p. 9. 
ambos, de um movimento de renovaçăo da arte brasileira que jamais desaparecerá das páginas de nossa história artística. Poderão desaparecer, talvez, as obras que produziu; mas o ideal de integração nacional que o motivou será sempre lembrado, pois representa um momento decisivo do pensamento brasileiro, claramente exposto nos escritos de Mánio de Andrade - que foi seu teórico, para a música, e que o realizou, na obra poética - magnificamente exemplificado nas partituras de Mignone, muitas das quais obedientes a um plano programático traçado pelo amigo"7.

Que Francisco Mignone conheceu o texto introdutório de Luiz Heitor antes da edição de A Parte do Anjo, é óbvio. "Si Alza la tela" acentua mais claramente que o silêncio de Mignone evidencia, ainda em 1947, a fidelidade que se firmara muitos anos antes, frente ao nacionalismo. Nāo quis, no caso, o confronto. Bem mais tarde, não se refere a Máno de Andrade, sempre com fina observação: "Tudo quanto eu escrevia ele criticava [...] Segundo ele dizia, o autor muito elogiado acaba numa burrice completa e absoluta" 8 . Năo haveria, por um lado, subjacente, a necessidade do mestre em manter a tutela absoluta, evitando o desgarramento do pupilo? e deste, a também necessidade de se fazer partidánio, mesmo que outros fatores determinassem um pluralismo distante da questão fechada, expresso pelo compositor em épocas diferentes, tanto em A Parte do Anjo como em escritos posteriores?

Quanto aos cinco textos de Francisco Mignone na obra em questāo, tem-se um apanhado bem abrangente, de síntese, do pensamento do autor duas décadas após os tempestivos anos do emergir de uma estética nacionalista proposta por Mário de Andrade.

Em A Parte do Anjo, Mignone é claro e ambíguo, posiciona o seu pensamento sem quaisquer amarras vernaculares... ou mesmo de intençōes, e se, sob determinado aspecto, repetiçōes integrais, plágios surgem a partir dos escritos bem anteriores de Mário de Andrade, sob égide outra, quando na originalidade mostra-se irreverente, contestador, demolindo a noçāo do compositor puro saido de si mesmo.

Ao discorrer, no primeiro dos ensaios, "Prelúdios. Coral e Fuga" (orientação individual), já parte de premissa plagiária, pois empresta o titulo da célebre obra para piano de César Franck. Tem-se a primeira senha para a série de argumentos que o defendem - $e$ aos outros - do plágio. sem quaisquer inibiçōes, ao contrário, plenamente imbuido do humor que sempre o caracterizou. Para tanto, não poupa nomear ilustres personagens que igualmente serviram-se do plágio desde um passado remoto. Plagiaram abertamente, para Mignone: Guilherme de Almeida; Máno de Andrade, contundentemente em Macunaíma; Virgílio e Camões, numa seqüência a partir da tempestade de Homero. A noção do plágio - a Europa mostra-se modelo onipresente nas influèncias captadas no Brasil - torna-se, no caso Mignone, uma das reais recuperaçōes a demonstrar que o oficialmente nacional, entendido pela intelligentzia paulista a respeito dele, encobriria intenções profun-

7. Idem. ibidem. p. 20. Grifos nossos.

8. Entrevista realizada por Carlos Roque e publicada na revista Interview. n. 49. São Paulo. Inter. maio 1982. p. 42. 
das. Tem-se, na realidade, no caso Mignone, o plágio multidirecional. Todavia, entende os perigos e o único anátema: "O plágio só é condenável quando feito com intenção de roubar o sucesso alheio"'. O plágio explicana todas as adesōes europeizantes e Mignone mostra-se irredutivel, pois, se questionado a respeito, "mandaria todos àquela parte", sendo, em síntese, o plágio o aproveitamento de "elementos fecundos da criação alheia"10.

Mário de Andrade reconheceria todas as facilidades que inclinavam Mignone à diferenciação. Este entendia-se virtuose, jamais negligenciaria esse fato, tendo inclusive temores em relação a esta qualidade. Compreende talento e técnica, sabendo-se possuidor do primeiro e amplo conhecedor da segunda. Considera contudo que a verdadeira pesquisa "tem de se exercer nas próprias essências profundas do meu ser e da minha música. E então a pesquisa se tomará uma dificuldade real, elevada, obstaculante, maltratando-me, prendendo-me dias e dias na sublime inquietação do procurar a soluçāo" ${ }^{11}$. Os problemas essenciais teriam de ser encontrados em exemplos específicos, como a expressividade psicológica da música brasileira, e, num mergulho, salienta dois autores, Villa-Lobos e Camargo Guarnieri - a serem expandidos no quarto texto -, não se sentindo rebaixado em estudar o resultado das pesquisas composicionais de um autor mais jovem. Nesse segmento, ao acrescentar manifestaçāo musical do povo, Mignone espelha-se em Mário de Andrade. "O que fazer? Estudar o populário e esses autores" 12 de Mignone, tornar-se-ia a extensão - plágio? - do questionamento de Mário de Andrade sobre as características musicais da raça: "Onde que estão? Na música popular"13.

Nessa busca da orientação individual, reconhece sempre o seu talento, mas haveria o empenho em " $[. .$.$] provocar uma inflaçāo do Eu, de forma a criar um$ grande orgulho que se sobreponha à vaidade"14. Desses dois sentimentos, salienta a superioridade dimensional do primeiro, único recurso para uma longa caminhada, diferente da vaidade, esta superficial.

Francisco Mignone, nessa efervescência visando ao descortinar, entenda-se, é capaz da prática plena, mas precisando policiar-se. Do final da década de 20 , passando-se pelo cinqüentenánio até a chegada dos oitenta anos, há poucas oscilaçōes quanto aos preceitos realmente aceitos por Mignone, excluindo-se obviamente a ampla acumulaçāo das técnicas. Em carta a Vasco Mariz, bem posteriormente, expande fronteiras: "Posso escrever uma peça em dó maior ou menor, sem dor nem pejo, assim como elaborar conceito de música tradicional, impressionista, dodecafōnica, serial, cromática, atonal, bitonal, politonal e quiçá, se me der na telha, de vanguarda, com toques concretos, eletrônicos ou desfazedores de multiplicadas faixas sonoras". E deixando ao largo quaisquer estéticas que poderiam se tomar

9. MIGNONE, Francisco. Op. cit. p. 40.

10. Idem, ibidem, loc. cit.

11. Idem, ibidem, p. 41.

12. Idem, ibidem, p. 42.

13. ANDRADE. Mário de. Ensaio sobre Música Brasileira. São Paulo, 1. Chiriato, 1928. p. 6.

14. MIGNONE. Francisco. Op. cit. p. 43. 
amarras: "Tudo se pode realizar em arte, desde que a obra traga uma mensagem de beleza e deixe no ouvinte a vontade de querer ouvir muitas vezes a obra. Não acontece isso também nas outras artes?"15.

Estas afirmaçōes corroboram toda uma posição literariamente embrionánia em A Parte do Anjo, no segmento orientaçāo individual, mas doravante plenas de todo espectro das técnicas conhecidas no inicio dos anos 80 . Quando em outra carta de 15 de junho de 1985, Mignone escrevia: "Junto vai A Parte do Anjo - você vai encontrar a minha maneira de ser como artista. Continuei e perdurarei sempre o mesmo"16, ratificava meses antes da'morte posiçōes que poder-se-iam entender elásticas - quanto à absorçāo das técnicas composicionais - no livro contidas $e$ expandidas na carta a Vasco Mariz. Ao se ler Mignone nas distâncias temporais, o seu engajamento com a pluralidade estética e com a beleza da mensagem pareceriam ser presentes emi seu mundo interior ${ }^{17}$.

No segmento onientação social, segundo capitulo de A Parte do Anjo, Mignone a par conceitos seus, visita à exaustão afirmações já expressas no Ensaio sobre Música Brasileira. O plágio, nessas passagens, é evidente. Verifica-se que a estética transmitida por Mário de Andrade, verbalmente e através dos escritos, permanecia aparentemente intacta. Quase vinte anos após, recorre ao Ensaio para apresentar a sua ligaçāo ao ideáno nacionalista, que outras passagens de $A$ Parte do Anjo desmentinam. A hipótese da camuflagem ganharia impulso. Escreve Mignone:

"Não, nāo sou um gênio inato [...] Se eu fosse gênio inato o meu destino era atingir toda a Humanidade. Não me incomodava com escolas, paises, tempos, raças, mandava tudo plantar batatas, para liberdade pura do meu gênio elevando a Humanidade. Mas si eu sou gênio feito, o meu destino è mais realista. mais prático, mais qualificado, e tenho que elevar a Humanidade naquilo em que ela é condicionada pelos seus imperativos pragmáticos e transitónios, isto è, tempo, raça. pais, escola. É curioso como os gênios feitos sāo nacionais" $1 \mathrm{~s}$.

É do Ensaio de Mário de Andrade a frase: "Se um artista brasileiro sente em si a força do gênio, que nem Beethoven e Debussy sentiram, está claro que deve fazer música nacional [...] E se o artista faz parte de $99 \%$ dos artistas e reconhece que nāo é gênio, entāo é que deve mesmo fazer arte nacional" 19 .

Na extensa digressão nesse capítulo de Mignone a respeito do gènio, do nacional, uma outra utilização de conceito evidencia a plena anuência com o pensamento de Mário de Andrade, sempre do Ensaio mais precisamente. A célebre

15. MARIZ, Vasco. História da Música no Brasil. Rio de Janeiro, Civilizaçảo Brasileira, 1981. p. 191.

16. Carta a J. E. M.

17. Sergei Prokotiev nāo teria realizado reflexóes concordes ao manifesto Idanov de 1948, que condenava - formalismo. propondo, em contrapartida. meios composicionais a atenderem o realismo soviético: mas na esséncia criativa continuando, ele. Prokofiev, o mnesmo?

18. MIGNONE. Francisco. Op. cit., p. 44-5.

19. ANDRADE, Mário de. Ensaio sobre Música Brasileira, ed. cit. p. 6. 
e polêmica boutade de Mário de Andrade, exaustivamente interpretada pelos pósteros: "Todo artista brasileiro que no momento atual fizer arte brasileira é um ser eficiente com valor humano. O que fizer arte internacional ou estrangeira, si não for gênio, é um inútil, um nulo. E é uma reverendissima besta" 20 teria a ratificação por parte de Mignone que, ao discorrer sobre o músico social e nacional, afirmaria: "[...] porém com exceçāo de Carlos Gomes e de Villa-Lobos (Guarani, Schiavo, Chôros, Amazônia, Alma Brasileira) que souberam criar sobre simbolos gerais, os outros foram, me perdoem, muito bestas"21. Reverendissima e perdoar pertenceriam ao mesmo patamar, com diferenças de nuances. Máno de Andrade refere-se aos não engajados como bestas, Mignone retroage no tempo, excetuando Carlos Gomes.

Possivelmente, o capitulo "A parte do Anjo", que dá nome ao conjunto de textos, esteja a pairar como a revelação do mundo interior de Mignone. Anjo e demônio, antagonismos de forças que sempre existiram na vida e obra do autor, a dimensionar o todo. Foi a existência dos contránios, expressos, assimilados, ego e uma espécie de alter-ego - Chico Bororó e as circunstâncias -, que substanciaram a composição musical tão diversificada, tão repleta de trouvailles desconcertantes, e mesmo as mais díspares obras têm a impressão digital, o estilo do autor. As composiçōes para piano, como exemplo, instrumento do qual foi eximio executante, mantêm em toda a longa trajetória do autor - apesar de tantas sendas percorridas - um fio condutor que faz entender ser do mesmo criador obras rigorosamente espalhadas no tempo. E esse fio é o idiomático técnico-pianístico ${ }^{22}$.

Que o compositor passava, nos anos em tomo do seu cinqüentenário, por forte crise existencial - mercê dos antagonismos criativos - é notóno e Luiz Heitor, testemunha, citando inclusive Mário de Andrade que, anos antes, já se apercebera dos dilemas de Mignone. Nesse terceiro capitulo, o compositor vive intensamente a presença da dúvida, graças, e muito, à incrivel versatilidade no quadro compositivo. Volta-se: Anjo e demônio, Bem e Mal, dúvida dinâmica, "que faz a curiosidade que perquire e busca penetrar no àmago das coisas [...] dúvida que desconfia, que faz o medo e me paralisa, como um sapo diante da cobra" 23 .

Sente-se que, do desalento, da desconfiança, do receio por que passava, Mignone busca forças que o impulsionavam após resignaçăo á aceitaçăo. $O$ discurso de Mignone, longe de qualquer espirito cartesiano, é plenamente sensitivo - intuitivo por vezes - onde o inefável e telúrico convivem nas divergências que tendem à harmonia. A comparação é sempre proposta bem elaborada: "É a atitude do individuo que tendo um calo no pé. em vez de compreender a fatalidade do calo, não admite a fragilidade da pele e corta logo os dois pés! Ora é aceitando a existência

20. Idem, ibidem, loc. cil.

21. MIGNONE, Francisco. Op. cit., p. 48.

22. Tipicidades idiomáticas são tratadas em: MARTINS, José Eduardo. A pianistica multilacetada de Francisco Mignone. Revista Música. São Paulo, Dept. Música-ECA-USP. v. 1. n. 2, p. 89-113. nov. 1990.

23. MiGNONE, Francisco. Op. cit.. p. 50. 
do calo, que eu consigo inventar um jeito de acabar com ele e continuar avançando até ... o próximo calo"24.

Esta aceitaçăo tomar-se-ia o passo não messiânico mas em direção consciente às dúvidas que podem levar ao aperfeiçoamento. Anjos e demônios impulsionam-no à auto-admiração $e$ ao desânimo. Ambigüidades em permanentes confrontos, que deságuam num descortinar novos horizontes, apesar do convivio com a pouca praticidade. Os interesses são outros. O "continuei e perdurarei sempre o mesmo " de 1985 - entenda-se a curiosidade - não seria resultante dialética e benfazeja do demônio não tão demônio assim - que quase quatro décadas precedentes levara-o a afimar: "Eu tenho sempre o meu demônio que me conduz à perversidade intelectual de dizer: "mas é isto mesmo que eu estou fazendo e sempre fiz"25? Naquela frase presente $e$ futuro, nesta, presente e passado, ambas pertencentes à extensão do caminho.

O quarto dos textos, "A música brasileira (predestinados e destinados)", curto, trata mais de uma resumida panorâmica de dois autores do que de problemas essenciais da música no país. Não há aprofundamentos. Têm interesse determinadas focalizações. O termo besta, emprestado do Ensaio sobre Música Brasileira de Mário de Andrade em texto anterior de Mignone, é esquecido no contexto. Dir-se-ia que o compositor tivera consciência da boutade. Os músicos do passado perdem a pejoração de bestas para terem outra referência, contudo sempre à distância: "Os antecessores guardo-os na respeitosa ordem cronológica em que honestos historiadores os colocarem" 26 . Curiosamente, o discurso oficial contrariaria o coloquial e a prática diária de Mignone. Teve a maior consideração pelo passado musical brasileiro, sobremaneira nas últimas décadas da existência.

A besta minúscula, sem horizontes, desaparece, e tal como numa visão fantasmagónica e mitológica, surge outra, essa telúnica e grandiosa, a Besta. "Villa-Lobos é a Besta, o elemento de irracionalidade irrompente, vulcânica, destruidora, colossal, no bom e no mau sentido. Villa-Lobos é genial? Não se sabe. Sentimo-lo genial pelo em que a música dele nos ilumina, nos força, nos desvirgina, nos sangra em nossas transitoriedades. [...] Villa-Lobos é a Besta, è uma força magnifica, apaixonante, mesmo sublime, das cavernas da irracionalidade. $O$ oposto ao sapient́ssimo e racionalíssimo Ravel"27. Toda essa apreciaçāo solidificar-se-ia ao longo e Villa-Lobos, a cada década, sofre o fenômeno da maior expansäo. Em pleno momento de vivência do colega, Mignone, com humor, aponta defeitos na feitura de certas obras: "É certo que ele jamais se preocupou em se dar um destino, mas ele é a Besta, forçado ao destino que vai tendo. E como é um safado consciente vai vencendo e se destinando, até com prejuizo da própria composição. $E$ ninguém poderá negar que até com a safadez, e fazendo besteiras incriveis, ele está se dando um forte e histónico destino"28.

24. Idem, ibidem, p. 50-1.

25. Idem, ibidem, p. 51.

26. Idem, ibidem, p. 52.

27. Idem, ibidem, loc. cit.

28. Idem, ibidem, p. 53. 


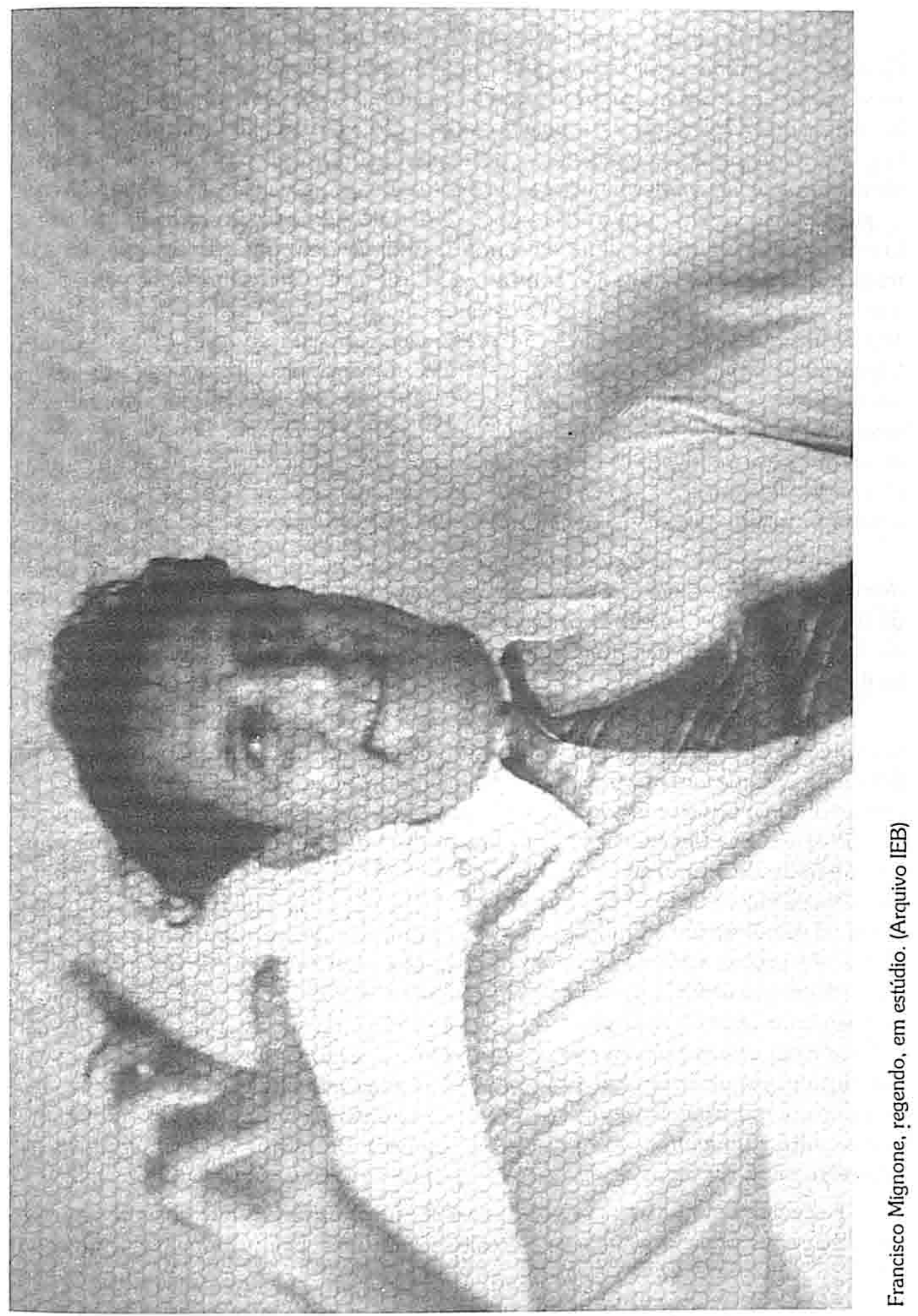


Mignone privilegia, sob aspecto outro, a grande capacidade de um mais jovem, Camargo Guamieri, que, ao não ouvir chamamentos alienigenas, "|...| está fazendo uma música muito mais profundamente brasileira, já expressivo-psicologicamente brasileira, que o Villa-Lobos e toda a nossa geraçäo" 29. Essa última afirmaçāo ratifica não ser Mignone o exemplo nítido desse mergulho brasilico. Contudo, continua afirmando que, sem determinados ascendentes, não podena Camargo Guarnieri ser o que é: "Mas, repito, sem o Villa-Lobos, Mánio de Andrade, Lorenzo Fernandez e Luciano Gallet ele nāo poderia de forma nenhuma, nem que fosse gênio, fazer a música que está fazendo [...] E com isto o Brasil teve o seu primeiro e verdadeiro músico purista"30. Estava-se a poucos anos da Carta aos Músicos e Críticos do Brasil, na qual essa necessidade de preservação purista se fazia oportuna para Camargo Guamien. A sua longa trajetória, a constância irredutivel aos ideais nacionalistas, foi-the bem e mal, e a esmerada escrita revelaria a pouca vontade de visitar vertentes teónicas emergentes. Permaneceria um purista. Sob prisma outro, as observaçōes de Mignone sobre Villa-Lobos e Camargo Guamieri ganham dimensão na medida em que, no fim do texto, evita conclusōes artístico-estéticas sobre a música brasileira, por suspeitá-las "apressadas ou perfunctórias"31.

Encerra o ciclo de textos a autovisão, datada de 1945, da ópera O Contratador dos Diamantes, em que o autor narra com profundo senso de humor as estréias da ópera no Rio de Janeiro e em Sāo Paulo, no ano de 1924, e episódios relativos às mesmas, e com não menos hilárias as peripécias junto a um empresário ludibriador.

A releitura de A Parte do Anjo - obra já citada ao largo por historiadores faz entender que, em plena turbulència estética no final dos anos 40, Mignone se posiciona oficialmente nacionalista, oficiosamente aberto a todas as correntes. Faz entender que o seu discurso ignora a posiçāo, essa sim, assumida in totum por Luiz Heitor, que busca, ao explicar o autor das Valsas de Esquina, construir, amparando-o, o muro de arrimo que seria Mário de Andrade. A armadilha e o despistamento preparados inconscientemente ou não por Mignone - necessidade de não submergir a sua criaçāo - atinge a ambos, o autor de Paulicéia Desuairada e o próprio Luiz Heitor. As provas evidentes ficanam reservadas à extensa produção do compositor, que percorreria absolutamente da l'aise gêneros e técnicas. Faz compreender que o engajamento oficial - premido, frise-se, por motivos da subsistência física e mental - demonstra que o fundamental de um autor, o estilo, uma das salvaguardas da perenidade, estaria presente nas criaçōes as mais antagônicas sob a égide das técnicas composicionais. O mesmo criador dos Seis Prelúdios entende pertinente a elaboraçāo de outra obra referencial, os Seis Prelúdios e Meio, síntese de procedimentos. Décadas de distância.

Recentemente, duas posiçōes básicas foram publicadas, naş quais a essência das discussōes poderia evidenciar perenidades ou não. Numa primeira, formulada

29. Idem, ibidem, loc. cil.

30. Idem. ibidem, p. 54.

31. Idem. ibidem, loc. cil. 
por Oswaldo Costa de Lacerda, Meu Professor Camargo Guarnieri, entende-se o fechamento unilateral quanto à questão nacionalista. A Europa é tratada por superada e exaurida ${ }^{32}$ (sic) e a Carta Aberta aos Músicos e Críticos do Brasil é exaltada. A inexistência do interlocutor competente à época de Mário de Andrade, a partir dos anos 20, propiciou o fácil enraizamento de suas teonas. Pareceria claro que estas, atravessando o século, foram entendidas em 1947 como duradouras por Luiz Heitor, mas mostrar-se-iam nos estertores através do depoimento de Oswaldo Costa de Lacerda ${ }^{33}$.

Uma segunda posição, hodierna, aberta, pluralista, seria formulada por Ricardo Tacuchian que, ao escrever sobre o Festival Sonidos de las Americas: Brasil, realizado em Nova lorque em 1996, entende cinco grandes tendências na música brasileira: uma primeira, denominada nos anos 60 e 70 de Música de Vanguarda; como segunda corrente, a presença de um neonacionalismo e os seus adeptos, exemplifica, "[...] dāo ênfase ao impulso rítmico dos tambores e fundem estes recursos com técnicas composicionais contemporâneas"; uma terceira, de caráter neo-romântico: "[...] com a exploraçāo de uma atmosfera do tipo New Age Music e com algumas grandiloqüências hollywoodianas", sendo que o tonalismo é plenamente assumido; como quarta tendência, define "[...) a de um comportamento estético'que tenta superar as velhas polaridades que definiram a música do século $\mathrm{XX}$ : velho/novo, tradição/renovação, tonal/atonal, conteúdo/forma, ocidental/oriental, nacional/universal, entre outras. (...) sendo chamada, por algumas pessoas, de pós-moderna"; e a última, "[...] de uma riqueza ilimitada e, ela própria, admite várias subdivisōes: a música eletro-acústica" 34 .

Năo sena dificil perceber que Mignone, em 1947 e na carta a Vasco Mariz, já antevia caminhos...

O espectro da tragédia, esta infelizmente a se mostrar a cada ano mais nítida, escaparia das discussōes estéticas ideológicas e politicas, para ser focado na imperiosa não-divulgação. Se vícios culturais mais claramente sentidos têm origem sobremaneira a partir do emergente movimento nacionalista dos anos 20 , pois os propósitos ficam definidos quanto ao que deveria ser divulgado e este era o da produção ligada à corrente voltada ao nacional, outros fatores implicariam a acentuação da crise.

$O$ silêncio se estenderia a todos os que morreram nas décadas a seguir. Enquanto presentes, a própria existência, os deslocamentos geográficos lógicos, sustentam a divulgação. O autor tem parcela nesta e a mesma se faz a partir de fatores referentes à produçāo, e tantas vezes pessoais, a determinarem até a aparência da qualidade. $O$ desaparecimento do compositor tem sido - exceçāo

32. Em 1939, Mário de Andrade já nảo se relerira à "insidiosa e morlifera iara internacional"? Cf. MIGNONE, Francisco. A Parte do Anjo. Op. cit., p. 61.

33. LACERDA, Oswaldo Costa de. Meu Prolessor Camargo Guarnieri. Revista da Sociedade Brasileira de Música Contemporäneo. Goiània, SBMC. a. 3, n. 3, p. 53-75, 1996.

34. TACUCHMN. Ricardo. O Brasil no Camegie Hall. Revista do Sociedade Brasiletra de Música Contemporánea. Rio de Janeiro, a. 3. n. 3, p. 81-2. 1996. 
única a Villa-Lobos quanto à internacionalização, e a uns pouquíssimos quanto à divulgação pelo menos em centros do Brasil - o eclipsar da obra. Sem o interesse da presença do autor, o intérprete perde a motivação - quando não causas escusas desviam-no do repertório - e a sombra, já sepulcral, toma-se escuridão completa.

Urge redescobrir tantos autores. Que não fique apenas na comemoração dos 100 anos a lembrança de Francisco Mignone, Lorenzo Femandez ou Pixinguinha, os três plenos da dedicaçăo ao criar. Poucas récitas estarāo a homenagear os dois primeiros; quanto ao terceiro, a grande mídia se ocupará, até adequadamente, em 1997. E deverá ser apenas isso.

Quanto a Mignone, a sua ausência nas programaçōes regulares é a evidência do empobrecimento de uma das culturas brasileiras. Midia e sociedades de concerto estariam dispostos ao resgate? Estaniam, por exemplo, dispostos a sugerir as obras de Mignone aos famosos conjuntos orquestrais estrangeiros que nos visitam? $\dot{\mathrm{E}}$ lamentável a quase certeza que leva ao nāo acreditar.

\section{THE ANGEL AND HIS METAMORPHOSIS}

ABSTRACT: Francisco Mignone in face the principles of the Nationalistic aesthetics proposed by Mário de Andrade. The need of adherence as a requirement for intellectual and artistic survival. A Parte do Anjo (The Angel's share), dated 1947, and the antagonisms. Themalics: plagiarize and skill, talent and technique, inborn genius and man made genius, national and international music, angel and devil, dynamic doubt and doubt with mistrust, Villa-Lobos and Camargo Guarnieri. Pluralism of the thought. A terminal Nationalisın and modern trends of the Brazilian music.

KEYWORDS: F. Mignone; A Parte do Anjo; pluralism of the thought. 